\title{
Yeast Rpn4 Links the Proteasome and DNA Repair via RAD52 Regulation
}

\author{
Daria S. Spasskaya ${ }^{1}$, Nonna I. Nadolinskaia ${ }^{2}$, Vera V. Tutyaeva ${ }^{1}$, Yuriy P. Lysov ${ }^{2}$, \\ Vadim L. Karpov ${ }^{2}$ and Dmitry S. Karpov $1, * \mathbb{C}$ \\ 1 Center for Precision Genome Editing and Genetic Technologies for Biomedicine, Engelhardt Institute of \\ Molecular Biology, Russian Academy of Sciences, Vavilov str. 32, 119991 Moscow, Russia; \\ drspssk@gmail.com (D.S.S.); tutyaeva@gmail.com (V.V.T.) \\ 2 Engelhardt Institute of Molecular Biology, Russian Academy of Sciences, 119991 Moscow, Russia; \\ nioriss@gmail.com (N.I.N.); lysov@eimb.ru (Y.P.L.); karpov@eimb.ru (V.L.K.) \\ * Correspondence: aleom@yandex.ru; Tel.: +7-499-135-98-01
}

Received: 4 September 2020; Accepted: 29 October 2020; Published: 30 October 2020

\begin{abstract}
Environmental and intracellular factors often damage DNA, but multiple DNA repair pathways maintain genome integrity. In yeast, the $26 \mathrm{~S}$ proteasome and its transcriptional regulator and substrate Rpn4 are involved in DNA damage resistance. Paradoxically, while proteasome dysfunction may induce hyper-resistance to DNA-damaging agents, Rpn4 malfunction sensitizes yeasts to these agents. Previously, we proposed that proteasome inhibition causes Rpn4 stabilization followed by the upregulation of Rpn4-dependent DNA repair genes and pathways. Here, we aimed to elucidate the key Rpn 4 targets responsible for DNA damage hyper-resistance in proteasome mutants. We impaired the Rpn4-mediated regulation of candidate genes using the CRISPR/Cas9 system and tested the sensitivity of mutant strains to $4-\mathrm{NQO}, \mathrm{mMS}$ and zeocin. We found that the separate or simultaneous deregulation of $19 \mathrm{~S}$ or 20S proteasome subcomplexes induced MAG1,DDI1, RAD23 and RAD52 in an Rpn4-dependent manner. Deregulation of RAD23, DDI1 and RAD52 sensitized yeast to DNA damage. Genetic, epigenetic or dihydrocoumarin-mediated RAD52 repression restored the sensitivity of the proteasome mutants to DNA damage. Our results suggest that the Rpn4-mediated overexpression of DNA repair genes, especially RAD52, defines the DNA damage hyper-resistant phenotype of proteasome mutants. The developed yeast model is useful for characterizing drugs that reverse the DNA damage hyper-resistance phenotypes of cancers.
\end{abstract}

Keywords: 26S proteasome; Rpn4; DNA repair; RAD52; RAD23; DDI1; CRISPR/Cas9

\section{Introduction}

Genome stability is often threatened by the actions of various environmental and intracellular sources of DNA damage. Environmental DNA-damaging factors include sun radiation, Earth's natural background radiation, industrial chemicals, and food mutagens [1]. The intracellular sources of DNA damage include mainly by-products of cellular metabolism (e.g., reactive oxygen or nitrogen species and alkylating agents). Each day, every cell experiences tens of thousands of DNA lesions of various types [2]. The most abundant are single-strand breaks (SSBs) and nitrogenous base losses, which account for approximately $75 \%$ of all detected DNA damage events resulting from dysfunctional DNA repair [2]. The direct actions of ionizing radiation, the replication of SSB-containing DNA fragments, and the effects of two SSBs near each other produce the most detrimental type of damage: DNA double-strand breaks (DSBs) [3]. If left unrepaired, some DNA lesions become mutations that largely contribute to the progression of pathologic states, such as neuro-degenerative diseases, cancer and ageing [4]. 
DNA damage induces a complex DNA damage response (DDR); as a part of this response, DNA repair pathways are activated [5]. These pathways restore genome integrity to prevent the accumulation of pathogenic mutations. The base excision repair (BER), nucleotide excision repair (NER), DNA mismatch repair (MMR), direct repair and translesion synthesis pathways address DNA damage on single strands. The homology-directed repair (HDR), non-homologous end joining (NHEJ) and microhomology-mediated end joining (MMEJ) pathways repair DSBs. A number of other cellular systems are activated as part of the DDR to facilitate and control the process of DNA repair. Control of the DNA repair enzyme levels is required to prevent the action of these enzymes upon the resolution of DNA damage, since the overexpression of some enzymes causes genome instability [6]. The ubiquitin-proteasome system is also activated during the DDR. Proteolysis may have several important functions during the DNA repair process. First, the $26 \mathrm{~S}$ proteasome controls the levels of DNA repair proteins and enzymes. Its known substrates include Rad4 [7] and DNA polymerase $\eta$ [8]. Second, proteolysis may serve as a driving force of the multistep DNA repair process by eliminating the components from preceding steps that may inhibit subsequent steps. Third, proteolysis is required to remove (1) proteins covalently attached to DNA [9] to give access to DNA damage sites, (2) stalled RNA-polymerase II [10] to reveal damaged DNA sites, and (3) histones to facilitate DNA dynamics [11]. Other components of the ubiquitin-proteasome system, e.g., ubiquitin and ubiquitin-like modifiers, such as SUMO, are also important players in DNA repair pathways. For example, the monoubiquitination of PCNA allows the loading of DNA translesion polymerases and the replication of damaged DNA strands [12]. Yeast Rpn4, a transcriptional master regulator and substrate of the proteasome $[13,14]$, is another important player in the DDR and is involved in resistance to various DNA-damaging agents. Several lines of evidence support this. First, RPN4 deletion sensitizes mutant yeast to DNA damage [15-17]. Second, the RPN4 gene is induced, and the Rpn4 protein accumulates, upon the action of DNA-damaging agents $[15,18,19]$. Third, the promoters of a number of DNA repair genes have Rpn4 binding sites $[19,20]$. Fourth, the Rpn4-dependent induction of the BER pathway [20] or of NER and HDR [19] is observed upon DNA damage. These data suggest that both the proteasome and Rpn4 are positive regulators of DNA repair processes. Paradoxically, proteasome dysfunction, caused by inhibitors [19], mutations in proteasomal genes [21-23] or decreased expressions of essential proteasomal genes [19,24], leads to yeast hyper-resistance to DNA damage induced by camptothecin, 4-nitroquinoline-1-oxide (4-NQO) or methyl methanesulfonate (MMS). Although the deletion of the RPN4 gene was also found to cause proteasome dysfunction, the mutant strains were sensitive to all DNA-damaging agents tested $[15-17,25,26]$. These data indicate that the proteasome may play a negative role in DNA repair, while Rpn4 is a positive regulator. Our previous data provide a clue to explain this paradox. We suggest that proteasome dysfunction stabilizes Rpn4 and that Rpn4-dependent DNA repair genes subsequently become overexpressed, after which the corresponding DNA repair pathways are hyper-activated. However, aside from the canonical Rpn4 binding site proteasome-associated control element (PACE), a number of DNA repair genes have PACE-like elements differing from PACE in one or two positions. It has been shown that Rpn4 has weak interactions with such elements $[27,28]$. These data question the direct involvement of Rpn4 in the regulation of DNA repair genes. Moreover, DNA repair genes should be regulated by several transcription factors; as such, the contribution of the Rpn4-mediated regulation of these genes to the DNA damage hyper-resistance phenotype of proteasome mutants is not clear.

Here, we show that the transcription of the key HDR gene RAD52 is directly controlled by Rpn4. The Rpn4-dependent upregulation of DNA repair genes defines the DNA damage hyper-resistance phenotype of yeast with impaired proteasome function. 


\section{Results}

\subsection{Deregulation of Essential Proteasomal Genes Induces Hyper-Resistance to DNA Damage}

We showed earlier that an impaired Rpn4-dependent regulation of genes encoding essential subunits of 20S proteolytic (PRE1 in the YPL strain) [19] or 19S regulatory (RPT5 or RPT3 in the YRL or mRPT3 strain) [24] proteasome subcomplexes increases cell viability during acute and chronic exposure to DNA-damaging agents, such as mMS and 4-NQO. In this work, we obtained strains bearing PACE mutations in the promoters of both the PRE1 and RPT5 proteasomal genes to deregulate both 20S and 19S proteasome subcomplexes (YPRL strain, Figure 1a). The YPRL strain was obtained by exchanging the Rpn4 binding site PACE with an XbaI restriction site in the RPT5 promoter on the genetic background of the YPL strain. Mutations were introduced by CRISPR/Cas9-induced template-dependent repair (see Materials and Methods). We confirmed that mutants with deregulated PRE1 displayed decreased 20S proteasome activity (Figure 1b). In contrast, RPT5 deregulation in the YRL strain led to increased 20S proteasome activity (Figure 1b). This result can be explained by the increased expression of 20S proteasome genes due to Rpn4 stabilization, as we previously showed [24]. Despite differences in 20S proteasome activity, all the mutant strains exhibited defects in 26S proteasome activity - they accumulated polyubiquitinated proteins upon heat shock (Figure 1c), and showed sensitivity to classic proteotoxic stresses such as heat shock and exposure to the toxic proline analogue L-azetidine-2-carboxylic acid, thus displaying impaired proteasome function (Figure 1d). However, the proteasome mutants were hyper-resistant to the DNA-damaging agents 4-NQO and mMS (Figure 1e). Notably, the rpn4- $\Delta$ mutant was sensitive to both proteotoxic and genotoxic agents. Therefore, while proteasome function was impaired in all strains, the strains with an intact RPN4 gene showed hyper-resistance to DNA damage.

\subsection{Identification of Rpn4-Dependent Genes Involved in the Cellular Response to DNA Damage}

Rpn4 is a well-known proteasome substrate [13] that is stabilized upon deregulation of either the $19 S$ or $20 S$ proteasome subcomplexes [19,24]. We suggest that the upregulation of Rpn4-dependent DNA repair genes by stabilized Rpn4 contributes to the observed DNA damage hyper-resistance phenotype of proteasome mutants. To perform a systematic search for Rpn4-dependent DNA repair genes, we used the available data from several yeast genome-wide transcriptomic studies [29-32]. First, we created a list of genes that were differentially regulated (greater than or equal to twofold) in the wild-type strain upon exposure to at least one of the DNA-damaging agents, including ionizing radiation and compounds that methylate or oxidize DNA. Second, we created a list of 269 yeast genes with at least one of the following elements in their promoters that may serve as Rpn4 binding sites: PACE (5'-GGTGGCAAA-3'), MAG1-associated control element (MACE; 5'-GGTGGCGAA-3') and RPN8-associated control element (RACE; 5'-AGTGGCAAA-3') [33]. Dubious reading frames, retroelements, tRNAs and ARSs were excluded from the list (Table S4). The possibility that Rpn4 interacts with PACE-like elements was proposed previously [33], and was later shown experimentally [27,34]. We found that 207 out of the 269 genes were differentially expressed upon DNA damage (Table S4). Next, we selected genes that may function in DNA repair according to Saccharomyces Genome Database (SGD) annotation. We excluded from this list genes that we [19] and others [35] have previously shown to be regulated independently of Rpn4, despite having Rpn4 binding sites. We ultimately obtained the following list of 15 genes: PRI1, EXO5, IRC20, SSL2, DEF1, BMH1, CUZ1, TMC1, HTB1, MSH3, ZWF1, MAG1, RAD52, $R A D 23$ and DDI. We investigated whether some of these genes were expressed in an Rpn4-dependent manner. Real-time qPCR (RT-PCR) showed that DEF1, MSH3 and SSL2 were not dependent on Rpn4 (Figure S2). However, MAG1, RAD23 and RAD52 behaved as Rpn4-dependent genes. The expression of these genes was consistent with the stress resistance phenotypes of the mutant strains (Figure 1e); their expression was decreased in the rpn4- $\Delta$ strain under both normal and DNA stress conditions, and overexpressed in all proteasome mutants (Figure 2). These data indicate that the Rpn4-mediated overexpression of these genes may contribute to the observed phenotypes of the proteasome mutants. 
(a)

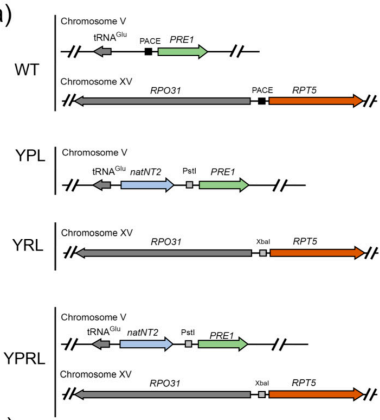

(c)

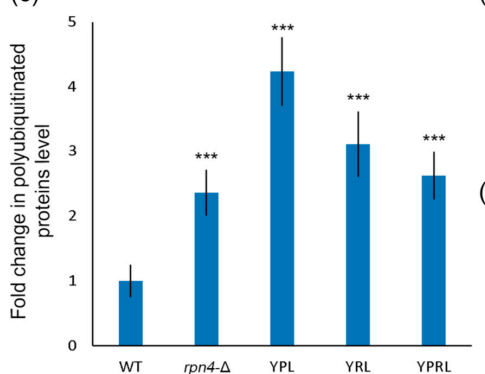

(b)

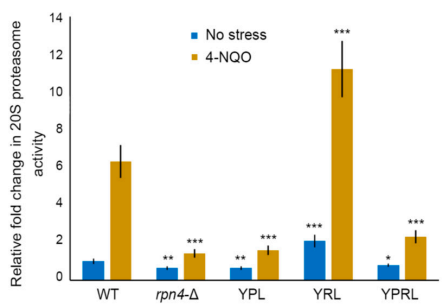

(d)
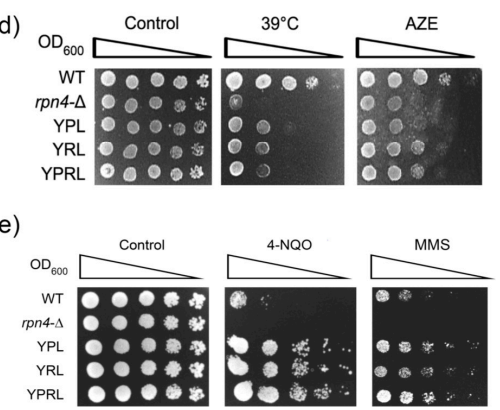

Figure 1. Yeast mutants with deregulated essential proteasomal subunits are hyper-resistant to DNA damage. (a) Schemes of the proteasomal mutant strains. (b) The $20 \mathrm{~S}$ proteasome activity in proteasome-mutant strains. The $20 \mathrm{~S}$ proteasome activity was measured in yeast exponential cultures under normal conditions or after 4-NQO treatment at a final concentration $1 \mu \mathrm{g} / \mathrm{mL}$ for $2 \mathrm{~h}$. The relative signal for the wild-type (WT) strain was set to 1 . The bar charts show the means $(n=3) \pm$ SDs. Statistical significance: * $p$ between 0.05 and 0.01 , ** $p$ between 0.01 and 0.005 and ${ }^{* * *} p<0.001$, according to Student's $t$ test. (c) Polyubiquitinated protein levels as quantified by ImageJ. The developed western blot picture is presented in Figure S1. The signal for polyubiquitinated proteins was normalized to the actin signal. The relative signal for the WT strain was set to 1. The values are the means $(n=3) \pm$ SDs. ${ }^{* * *} p<0.001$, according to Student's $t$ test. (d) The proteasomal mutant strains were sensitive to proteotoxic conditions. The plates were incubated for 4 days under heat shock conditions or 3 days in the presence of $100 \mu \mathrm{g} / \mathrm{mL}$ L-azetidine-2-carboxylic acid (AZE). (e) The proteasomal mutant strains were hyper-resistant to DNA damage. The plates were incubated for 4 days at $30{ }^{\circ} \mathrm{C}$. 4-NQO was used at a concentration of $0.75 \mu \mathrm{g} / \mathrm{mL}$. mMS was used at a concentration of $0.017 \%$.

(a)

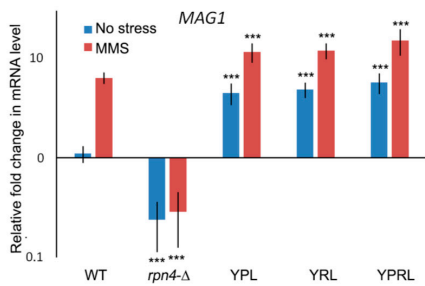

(b)

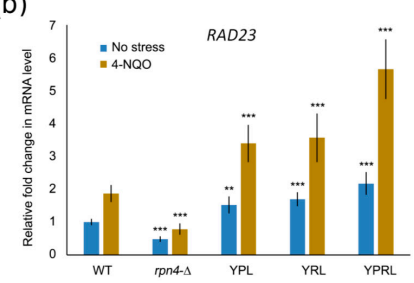

(c)

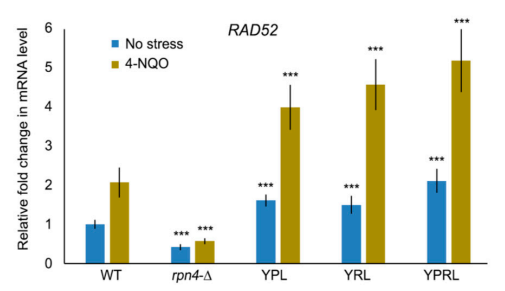

Figure 2. Rpn4-dependent DNA repair genes are upregulated in proteasome-mutant strains. The mRNA expression levels of MAG1 (a), RAD23 (b) and RAD52 (c) were measured by RT-PCR under normal conditions, after 4-NQO treatment at a final concentration of $2 \mu \mathrm{g} / \mathrm{mL}$ for $45 \mathrm{~min}$, or after mMS treatment at a final concentration of $0.2 \%$ for $30 \mathrm{~min}$. ACT1 was used as a reference. The relative mRNA level in the wild-type strain under normal conditions was set to 1 . The bar charts show the means $(n=3) \pm$ SDs. Statistical significance: ${ }^{* *} p$ between 0.01 and 0.005 and ${ }^{* *} p<0.001$, according to Student's $t$ test. 


\subsection{Deregulation of Rpn4-Dependent DNA Repair Genes Sensitizes Mutant Yeast to DNA Damage}

The identified Rpn4-dependent genes represent three different DNA repair pathways. RAD23 encodes a protein that functions in NER [36,37]. The RAD23 promoter contains the PACE-like element MACE, and Rpn4 is involved in the regulation of this gene [18,20]. MAG1 encodes 3-methyl-adenine DNA glycosylase, which initiates BER. The MAG1-DDI1 bidirectional promoter contains two MACEs. Although the interaction of Rpn4 with MACE in the MAG1-DDI1 promoter has not been shown by classical methods [38], Rpn4 is required for stress-induced MAG1 expression [20,39]. Earlier, using a highly sensitive DNA adenine methyltransferase identification (DamID) assay, we showed that Rpn4 interacts with the MAG1-DDI1 promoter, and we used a lacZ assay to show that the proximal MACE largely contributes to Rpn4-dependent MAG1 regulation [39]. RAD52 is a key member of the group of RAD52 epistasis genes, and is involved in DSB repair and recombination in yeast [40]. The RAD52 promoter contains the PACE-like element RACE at the $-72 \mathrm{nt}$ position relative to the start codon. Therefore, this site is located within the typical region for PACE or PACE-like elements in proteasomal genes and other Rpn4-dependent genes [41,42]. Earlier, we showed that RAD52 expression is regulated in an Rpn4-dependent manner [19].

The promoters of these DNA repair genes contain binding sites for other transcription factors. Therefore, the contribution of Rpn4 to the regulation of these genes and the DNA damage resistance phenotype is unclear. To elucidate the role of Rpn4, we created mutant yeast strains bearing mutations of the PACE-like elements in the promoters of genes of interest (Figure 3a). The GC-rich part of these elements was replaced with restriction endonuclease sites by CRISPR/Cas9-induced template-dependent repair. Since the bidirectional MAG1-DDI1 promoter has two MACE sites, we obtained mutant strains with mutations of MACE proximal to MAG1 (MAG1-pM) and both proximal and distal MACE (MAG1-pdM). Additionally, we obtained a double mutant strain, RMdM, bearing mutations of proximal MACE in the MAG1-DDI1 promoter and MACE in the RAD23 promoter. RT-PCR showed that in the mutant strains, both the normal and DNA damage-induced expression of RAD52 and RAD23 returned to the levels observed in the rpn4- $\Delta$ strain (Figure $3 b, c$ ). While MACE-mutant MAG1 expression under normal conditions was several-fold higher than that in the rpn4- $\triangle$ strain, the stress-induced level of MAG1 in the MACE-mutant was indistinguishable from that in the rpn4- $\triangle$ strain (Figure 3d). Thus, we conclude that the DNA damage-mediated induction of RAD52, RAD23 and MAG1 DNA repair genes is largely dependent on Rpn4, which acts via PACE-like elements. Next, to elucidate the contribution of the Rpn4-dependent regulation of DNA repair genes to the sensitivity of the mutant strains, we tested their resistance to DNA-damaging agents. In addition to 4-NQO, which produces NER substrates, and MMS, which creates BER substrates, we used the antibiotic zeocin, which induces the formation of DSBs and activates several HDR genes, including $R A D 52$, which is absolutely required for zeocin stress survival [43]. According to the results obtained, RAD52 deletion or deregulation renders mutant cells sensitive not only to zeocin but also to 4-NQO or mMS. Earlier, it was shown that RAD52 is also important for yeast resistance to another DNA alkylating agent, MNNG [44], and to oxidative DNA damage [45]. Active derivatives of metabolized 4-NQO may generate reactive oxygen species that, in turn, induce oxidative DNA damage [46]. Moreover, closely opposed SSBs, as intermediates in NER or BER pathways, may produce highly toxic DSBs [3], which are substrates for Rad52 and other components of HDR. While MAG1 deletion renders cells hypersensitive to mMS, MAG1 deregulation has no effect on yeast's sensitivity to mMS (Figure 3e). Compared with the rad23- $\Delta$ mutant, the mutant strain mRAD23 with deregulated RAD23 (Figure 3e) was also resistant to 4-NQO (Figure 3f). A possible explanation for such phenotypes among MAG1 and $R A D 23$ mutants is that despite decreased expression, the quantity of the produced enzyme is sufficient to cope with the corresponding DNA damage. Unexpectedly, the double mutant RMdM was sensitive to all three agents (Figure 3e). Since MAG1 is not required for 4-NQO resistance (Figure 3e), we suspect that its neighboring gene DDI1 contributes to the RMdM phenotype. Indeed, RT-PCR showed that DDI1 was an Rpn4-dependent gene, and its expression was decreased in the RMdM mutant upon 4-NQO stress (Figure 3g). DDI1 encodes a multi-domain protein with a ubiquitin-like domain, 
a ubiquitin-interacting domain and an aspartic protease domain [47]. DDI1 has several molecular functions, including participation in the DDR response to mMS [48,49]. Interestingly, the mRAD52 mutant displayed the most severe phenotype of sensitivity to DNA damage, almost identical to the phenotype of the rad52- $\Delta$ strain (Figure 3f). To prove that the mRAD52 phenotype was caused by RAD52 deregulation rather than by some CRISPR/Cas9 off-target effect or spontaneous mutations, we transformed mRAD52 with a plasmid encoding RAD52 under the control of its native promoter. Indeed, RAD52 complementation restored mRAD52's resistance to DNA damage (Figure $3 \mathrm{~h}$ ). These data suggest that Rpn4 is a critical regulator of RAD52 function. Notably, an extra copy of RAD52 led to the hyper-resistance of the wild-type strain to 4-NQO (Figure 3h), which suggests that the overexpression of DNA repair genes may provide hyper-resistance to DNA-damaging agents.

Additionally, we measured the 20S proteasome activity, and found that it is not altered in the mutants with impaired Rad52 function (Figure S3). These results suggest that the severe sensitivity to DNA damage of RAD52 mutants is independent of proteasome proteolytic function.
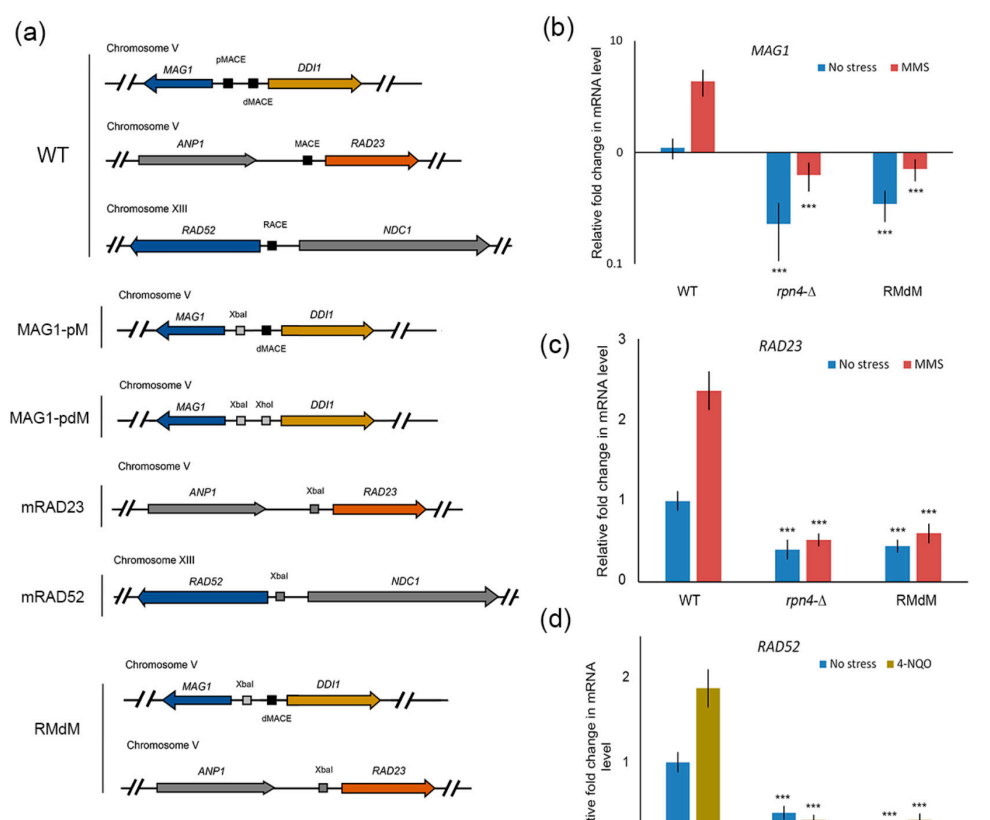

(d)
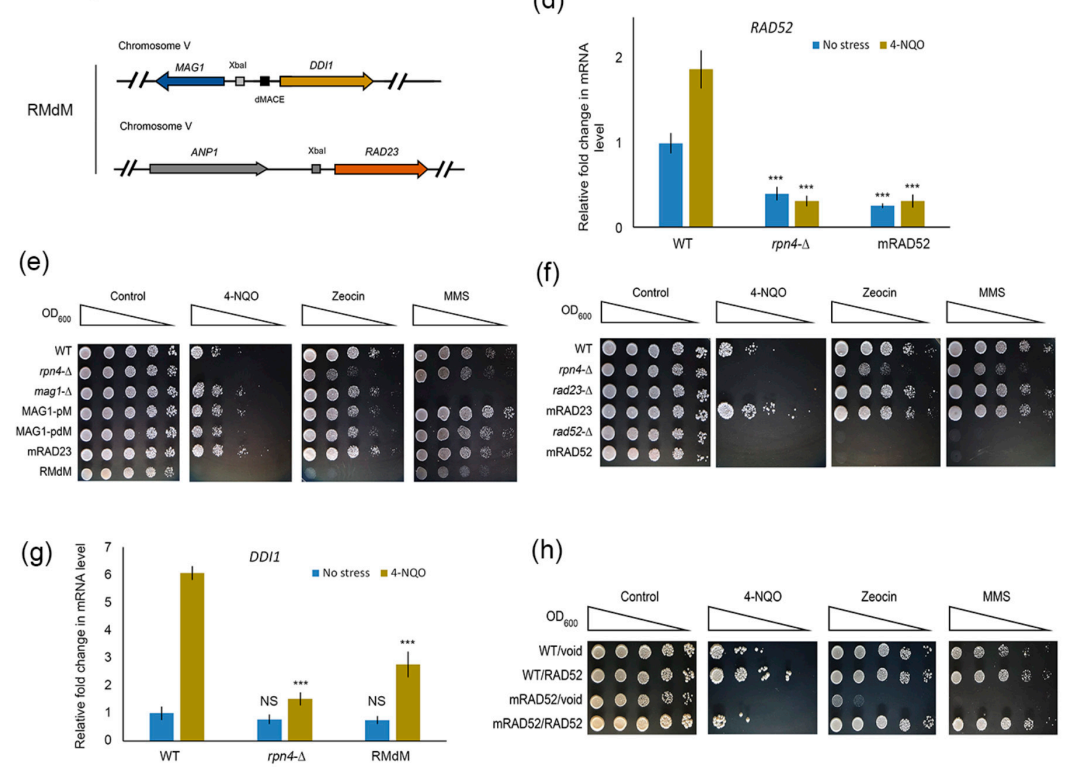

Figure 3. Deregulation of Rpn4-dependent DNA repair genes sensitizes yeast to DNA damage. (a) Scheme of yeast mutants bearing Rpn4 binding site (MACE or RACE) mutations in the promoter regions of the MAG1-DDI1, RAD23 and RAD52 DNA repair genes. Mutations were introduced into the yeast genome using CRISPR/Cas9-induced template-dependent repair. Both normal and stress-induced expression of MAG1 (b), RAD23 (c) and RAD52 (d) were impaired in strains with mutated Rpn4 binding sites. Exponentially grown cultures were treated with $2 \mu \mathrm{g} / \mathrm{mL} 4-\mathrm{NQO}$ for $45 \mathrm{~min}$ or $0.2 \% \mathrm{mMS}$ for $30 \mathrm{~min}$ at $30^{\circ} \mathrm{C}$. mRNA levels were measured by RT-PCR and normalized to ACT1. The relative mRNA 
level in the wild-type (WT) strain under normal conditions was set to 1 . The bar charts show the means $(n=3) \pm$ SDs. Statistical significance: ${ }^{* * *} p<0.001$, according to Student's $t$ test; (e-f) Results of the stress resistance test for mutant strains with deregulated MAG1, RAD23 and RAD52 genes. DNA-damaging agents were used at the following concentrations: 4-NQO, $0.75 \mu \mathrm{g} / \mathrm{mL} ; \mathrm{mMS}, 0.01 \%$; and zeocin, $250 \mu \mathrm{g} / \mathrm{mL}$. The plates were incubated for 4 days at $30{ }^{\circ} \mathrm{C}$; (g) RT-PCR showed that the mutation of MACE proximal to the MAG1 gene in the MAG1-DDI1 bidirectional promoter decreased the expression of DDI1 under stress conditions. The relative mRNA level in the WT strain under normal conditions was set to 1 . The bar charts show the means $(n=3) \pm$ SDs. Statistical significance: NS, non-significant; ${ }^{* *} p<0.001$, according to Student's $t$ test. (h) A plasmid with RAD52 under the control of the native promoter restored resistance to DNA damage in the mRAD52 mutant strain. DNA-damaging agents were used at the following concentrations: 4-NQO, $0.75 \mu \mathrm{g} / \mathrm{mL} ; \mathrm{mMS}, 0.012 \%$; and zeocin, $250 \mu \mathrm{g} / \mathrm{mL}$. The plates were incubated for 5 days at $30^{\circ} \mathrm{C}$.

\subsection{Rpn4 Directly Regulates RAD52 via a PACE Variant}

Little is known about the transcriptional regulation of $R A D 52$, so we sought to clarify whether Rpn4 regulates this gene directly or indirectly. Using a lacZ reporter system, we found that RACE deletion or substitution with the XbaI restriction site impaired mMS-induced Rad52 activation (Figure 4a). Additionally, we used western blotting to show that the Rad52 level is decreased in the rpn4- $\Delta$ strain (Figure $4 \mathrm{~b}, \mathrm{c}$ ). To investigate the ability of Rpn 4 to bind the RACE sequence in the RAD52 promoter, we performed DamID. According to the DamID results, Rpn4 is recruited to the wild-type RAD52 promoter (Figure 4d). To confirm that Rpn4 binds to the RAD52 promoter via the RACE sequence, we created a mutant strain with a RACE-to-XbaI mutation using the CRISPR/Cas9 system. Indeed, Rpn4 was not recruited to the mutated RAD52 promoter (Figure 4d). Thus, we conclude that Rpn4 regulates $R A D 52$ directly via interaction with RACE. Rad52 expression at the protein level is well correlated with its mRNA level. To test whether Rpn4 stabilization is sufficient for RAD52 induction, we measured the RAD52 mRNA levels in the wild-type strain expressing Rpn4-stabilized forms (Figure 4e). The RT-PCR results proved that Rpn4 stabilization is sufficient for RAD52 overexpression. To our knowledge, Rpn4 is the first described transcriptional regulator for yeast $R A D 52$.

\subsection{Impaired Rpn4-Dependent Regulation of DNA Repair Genes Restores the Sensitivity of Proteasome Mutants to DNA Damage}

Our results suggest that the Rpn4-dependent induction of RAD23 together with DDI1 or RAD52 alone is crucial for yeast resistance to DNA damage. To test whether the Rpn4-dependent overexpression of DNA repair genes provides proteasome mutants with hyper-resistance to DNA damage, we created two mutant strains using the CRISPR/Cas9 system (Figure 5a). In the first strain, YPL-RMdM, we introduced a PACE mutation in the PRE1 promoter on the genetic background of the RMdM strain. In the second strain, YPL-mRAD52, we introduced a RACE mutation in the RAD52 promoter on the genetic background of the YPL strain. The presence of mutations was verified by PCR amplification of the mutated promoters, followed by restriction analysis (Figure S5). Deregulation of both PRE1 and RAD52 genes in the yeast double mutants was confirmed by RT-PCR (Figure S6). The stress resistance test showed that the obtained mutants were sensitive to DNA damage, with the YPL-mRAD52 strain displaying the most severe phenotype (Figure $5 b$ ). Our results suggest that the Rpn4-dependent overexpression of DNA repair genes, especially $R A D 52$, defines the DNA damage hyper-resistance phenotype of proteasome mutants. 
(a)
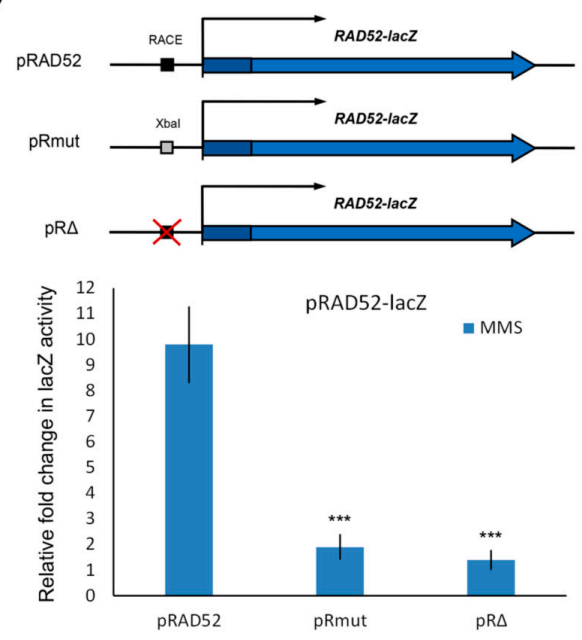

(d)
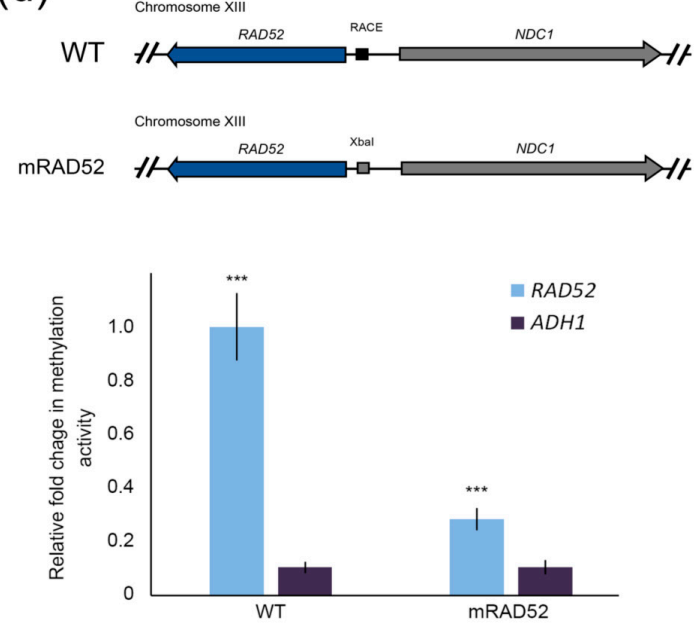

(b)

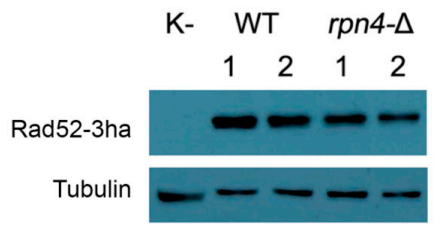

(c)

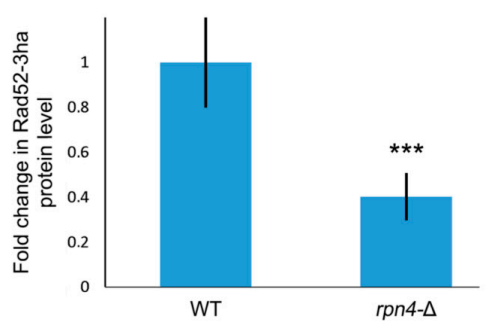

(e)

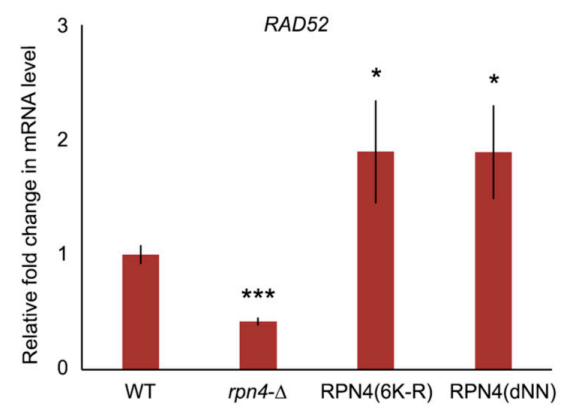

Figure 4. Rpn4 regulates RAD52 directly via RACE. (a) RAD52-lacZ translational fusion reporters showed that the RACE element is required for DNA damage-mediated induction of RAD52. Schemes of the RAD52-lacZ reporters used are given. pRAD52 bears the RAD52 promoter and $5^{\prime}$ part of the $R A D 52$ ORF fused in-frame to the lacZ gene. pRmut differs from pRAD52 only by substitution of the $5^{\prime}$-AGTGGC-3' part of the RACE element with the XbaI site (5'-TCTAGA-3'). The pR $\Delta$ construct differs from pRAD52 by deletion of the RACE element. The lacZ activity is reported relative to that of the pR $\Delta$ construct. The bar charts show the means $(n=3) \pm$ SDs. Statistical significance: NS, non-significant; ${ }^{* * *} p<0.001$, according to Student's $t$ test. (b) Western blot analysis of Rad52-3ha levels in the wild-type (WT) and rpn4- $\Delta$ strains. Numbers designate independent colonies. The full image of the developed western blot is presented in Figure S4. (c) Rad52-3ha levels quantified by ImageJ software. The signal for Rad52-3ha was normalized to the tubulin signal. The relative signal for the WT strain was set to 1 . The values indicate the means $(n=4) \pm$ SDs. ${ }^{* * *} p<0.001$, according to Student's $t$ test. (d) RACE mutation inhibited the Rpn4 interaction with the RAD52 promoter. The methylation signal of the Dam-Rpn4 chimeric reporter protein was normalized to the signal from the mutant reporter Dam-Rpn4(C-A) with impaired Rpn4-binding activity. The ADH1 gene is not an Rpn4 target and was used as a negative control. The relative Dam-Rpn4 signal on the RAD52 promoter in the WT strain was set to 1 . The bars and error bars are the means $(n=3) \pm$ SDs. ${ }^{* * *} p<0.001$, according to Student's $t$ test. (e) Rpn4 stabilization was sufficient to induce RAD52. The mRNA level of RAD52 in the WT strain expressing stabilized Rpn4 forms was measured using RT-PCR. Rpn4 was stabilized by the deletion of degradation signals (RPN4-dNN) or the mutation of all six N-terminal lysines that contribute to Rpn4 polyubiquitination (Rpn4(6K-R)). The RAD52 mRNA level in the WT strain was set to 1 . The values are the means $(n=3) \pm$ SDs. ${ }^{*} 0.01<p<0.05,{ }^{* * *} p<0.001$, according to Student's $t$ test. 
(a)
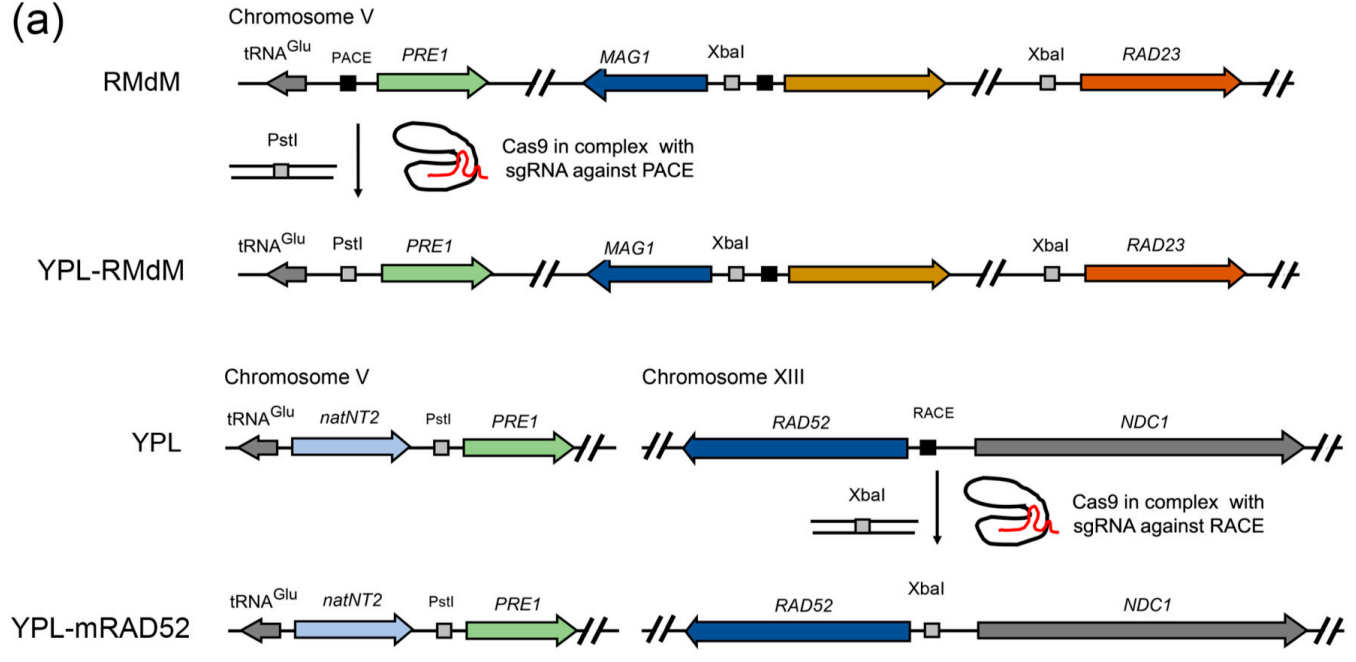

(b)

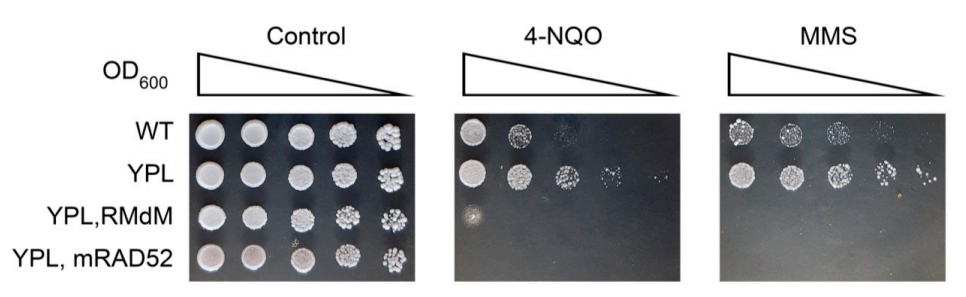

Figure 5. Deregulation of Rpn4-dependent DNA repair genes causes sensitivity to DNA damage in proteasome-mutant strains. (a) Schemes for the creation of mutants with deregulation of both PRE1 and DNA repair genes. Mutations were introduced by CRISPR/Cas9-induced template-dependent repair. (b) The deregulation of DNA repair genes on a YPL background sensitizes mutant yeast to DNA damage. DNA-damaging agents were used at the following concentrations: 4-NQO, $0.7 \mu \mathrm{g} / \mathrm{mL} ; \mathrm{mMS}, 0.016 \%$. The plates were incubated for 4 days at $30^{\circ} \mathrm{C}$.

\subsection{CRISPR-Mediated RAD52 Repression Decreases the Resistance of Proteasome Mutants to DNA Damage}

Mutant yeast may adapt to mutations in important genes. To confirm the results of the mutation experiments through an orthogonal approach, we performed a CRISPR repression experiment. Taking advantage of naturally occurring protospacer-adjacent motifs (PAMs) in the Rpn4 binding sites, we designed short (14 nt) spacers to target PACEs or RACEs in the promoters of PRE1, RPT3 or RAD52 (Figure 6a). SpyCas9 in complex with a short spacer should bind the target element, but not cleave it. Therefore, SpyCas9 should interfere with the Rpn4-dependent regulation of the corresponding genes. Recently, we used such an approach to inhibit the Rpn4-dependent expression of PRB1, one of the key autophagy genes [50]. RT-PCR confirmed the repression of the CRISPR-targeted genes (Figure 6b). The CRISPR-mediated repression of proteasomal genes in the wild-type strain clearly reproduced the 4-NQO hyper-resistant phenotype of proteasome mutants (Figure 6c). In addition, RAD52 repression in the wild-type strain (Figure 6c) as well as in the proteasome mutants (Figure 6d) decreased yeast resistance to DNA damage. Notably, RAD52 repression in the YRL strain had mild effects on YRL resistance to DNA damage. Since the $19 \mathrm{~S}$ regulatory subcomplex may participate in the DNA repair process independently of the $20 \mathrm{~S}$ proteasome [51,52], this could complicate the mutant yeast response to some types of DNA damage. 
(a)

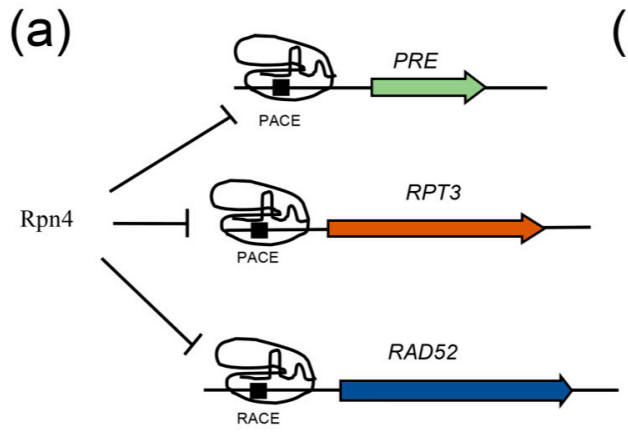

(b)

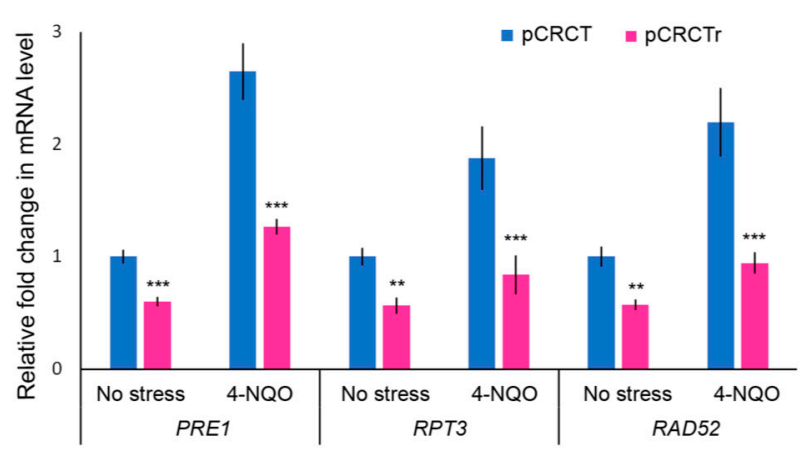

(c)

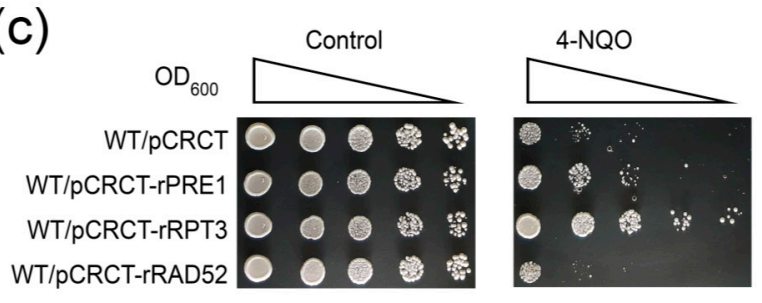

(d)

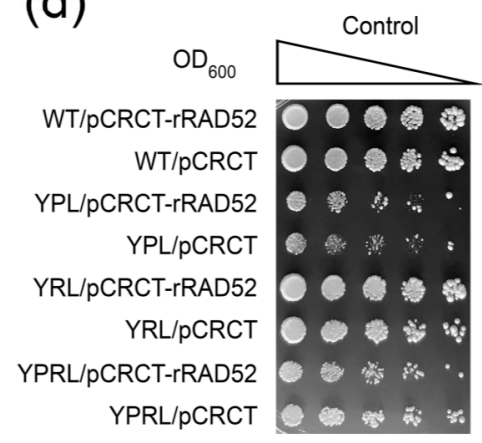

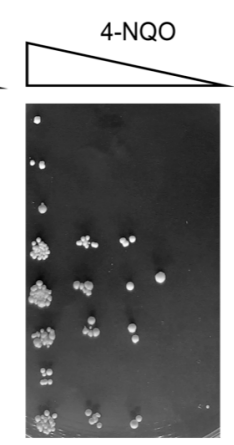
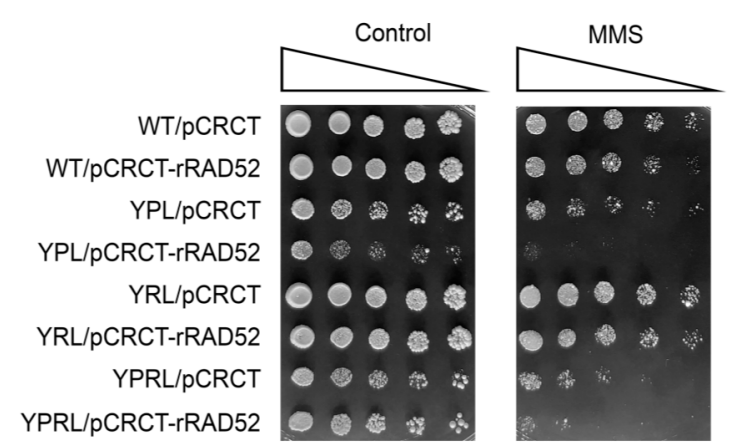

Figure 6. CRISPR/Cas9-mediated repression of proteasomal and RAD52 genes. (a) Scheme of the experiment. In complex with a short sgRNA, SpyCas9 binds to the PACE or PACE-like element, thereby inhibiting Rpn4 binding. (b) RT-PCR confirmed the CRISPR/Cas9-mediated repression of proteasomal and RAD52 genes in the wild-type (WT) strain both under normal conditions and upon 4-NQO treatment ( $2 \mu \mathrm{g} / \mathrm{mL}$ for $45 \mathrm{~min}$ ). The mRNA level of the corresponding gene in the WT strain transformed with the empty pCRCT vector was set to 1. pCRCTr denotes the WT strain transformed with the pCRCT plasmid bearing a short spacer against PACEs in the PRE1 or RPT3 proteasomal genes or RACE in the RAD52 promoter. The values are the means $(\mathrm{n}=3) \pm$ SDs. ${ }^{* *} 0.05<p<0.001$, *** $p<0.001$, according to Student's $t$ test. (c) CRISPR/Cas9-mediated repression of the proteasomal gene PRE1 or RPT3 induced hyper-resistance to 4-NQO, while RAD52 repression sensitized yeast to 4-NQO. (d) CRISPR/Cas9-mediated repression of RAD52 sensitized yeast mutants with deregulated proteasomal subunits to DNA-damaging agents. Concentrations of the DNA-damaging agents used: 4-NQO, $0.85 \mu \mathrm{g} / \mathrm{mL}$; mMS, $0.015 \%$. The plates were incubated for 5 days at $30{ }^{\circ} \mathrm{C}$.

\subsection{Dihydrocoumarin (DHC) Reverses the DNA Damage Hyper-Resistance Phenotype of Proteasome Mutants}

DHC, a natural compound found in Melilotus officinalis (sweet clover), is characterized as an inhibitor of the yeast NAD-dependent histone deacetylase (HDAC) Sir2 [53]. Recently, it has been shown that DHC, through HDAC inhibition, suppresses yeast HDR via RAD52 repression [54]. We sought to test whether the DHC-mediated chemical inhibition of RAD52 expression in proteasome mutants sensitizes them to DNA damage. Indeed, the stress resistance test showed that in the presence of DHC, the proteasome mutants formed colonies with, at best, the same rate as the wild-type strain, thereby showing no DNA damage hyper-resistance phenotype (Figure 7). 

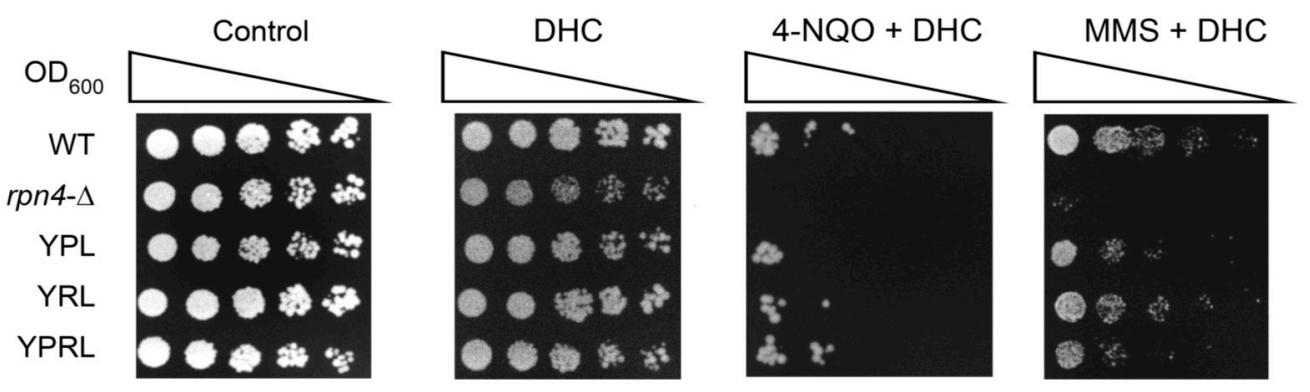

Figure 7. DHC reverses the DNA damage hyper-resistance phenotype of proteasome mutants. Concentrations of chemicals used: DHC, $3 \mathrm{mM}$; 4-NQO, $0.45 \mu \mathrm{g} / \mathrm{mL} ; \mathrm{mMS}, 0.0175 \%$. The plates were incubated for 4 days at $30{ }^{\circ} \mathrm{C}$.

\section{Discussion}

We found that the Rpn4-dependent overexpression of the DNA repair genes RAD23, DDI1, and especially RAD52 provides hyper-resistance to various DNA-damaging agents in yeast mutants with impaired 26S proteasome functions. The genetic, epigenetic or chemical inhibition of RAD52 expression restores sensitivity to DNA damage in the proteasome-mutant strains.

The characterization of the cellular response to DNA damage, particularly the mechanisms of DNA repair, has important medical applications for understanding and treating pathologies such as cancer, neurodegenerative diseases and ageing [55]. Moreover, it is important to improve the genome editing technologies that rely on cellular DNA repair pathways [56].

We here show that the Rpn4-dependent regulation of RAD23 and DDI1 or of RAD52 alone is crucial for yeast survival upon exposure to various DNA-damaging agents. Both RAD23 and DDI1 encode highly conserved proteins that possess ubiquitin-associated (UBA) and ubiquitin-like (UBL) domains. Therefore, they function as adaptor proteins in the ubiquitin-dependent protein degradation pathways by delivering substrates to the proteasome [57,58]. However, these proteins also have distinct functions in DNA repair pathways. Rad23 in complex with Rad4 senses DNA damage [36]. Ddi1 may function as an aspartic protease and assist in the removal of proteins cross-linked to DNA, e.g., the topoisomerase I cleavage complex (topoisomerase I-DNA covalent complex, TopIcc) and RNA polymerase II [48]. Additionally, Rad23p and Ddi1p may heterodimerize via their UBA domains [59], which may indicate that they exert coordinated actions. We found that the deregulation of RAD23 or DDI1 alone resulted in no visible phenotype (Figure 3e,f). However, the deregulation of both genes sensitized yeast to all DNA-damaging agents tested, especially 4-NQO (Figure 3e). Since both proteins may function as proteasome adaptors, they may have degenerated functions, e.g., the degradation of proteins that become ubiquitinated proteasome substrates upon DNA damage, and thus each may compensate for a decrease in the concentration of the other. It is tempting to speculate that these proteins may function in the same NER pathway. NER may participate in the removal of DNA-protein crosslinks [60]. However, NER cannot operate on peptides or proteins larger than $10 \mathrm{kDa}$ [61]. Thus, TopIcc or stalled RNA polymerase II cannot be processed by NER directly. Ddi1-induced proteolytic cleavage of TopIcc or RNA polymerase II may remove the obstacles and permit the Rad23/Rad4 complex to sense the damaged DNA locus and initiate NER. 4-NQO may stimulate the trapping of Top1cc by inducing SSBs or producing active intermediates that covalently bind to purines $[62,63]$. Camptothecin and other anticancer topoisomerase I inhibitors can trap Top1cc via specific binding to topoisomerase I-DNA complexes [64]. DD1I expression is increased in many cancer cell lines [65]. Thus, we predict that cancers may resist topoisomerase I inhibitors via RAD23 and DD11 upregulation.

RAD52 encodes the key player in yeast DNA homologous recombination. Little is known about $R A D 52$ transcriptional regulation, since it is considered to be regulated mainly at the post-translational level [66]. Previous studies have shown that RAD52 is induced during meiosis [67], upon exposure to DNA-damaging agents such as mMS, X-rays, and UV [68], and in proteasome mutants (pup1-1, cim5-1, and pre1-1 pre2-2) [69]. RAD52 overexpression, mediated by the strong constitutive ENO1 and 
controllable GAL1 promoters, does not significantly alter yeast survival upon acute mMS exposure [70]. Our results corroborate these observations and show that an additional copy of the RAD52 gene provided by a plasmid only slightly increases yeast resistance to chronic mMS stress (Figure $3 \mathrm{~h}$ ). However, an additional RAD52 copy provides hyper-resistance to 4-NQO (Figure 3h). Our data suggest that $R A D 52$ overexpression plays an important role in 4-NQO resistance.

Yeast is a convenient model for mechanistic studies on cellular responses to DNA-damaging anticancer drugs [71]. Therefore, our results might have significance for therapeutic applications. There are obvious differences in the molecular mechanisms by which yeast and mammalian cells cope with DNA damage; however, despite these differences, yeast may still serve as a useful model for research into HDR-mediated cellular responses to anticancer drugs. This is exemplified by the similar mechanism by which curcumin acts on yeast and multiple myeloma (MM) cells. Curcumin is an HDAC inhibitor that, similar to DHC, represses yeast RAD52 [72]. The bortezomib, melphalan and prednisone (VMP) regimen that includes melphalan, a DNA-alkylating and cross-linking drug, has been reported to be highly effective in the initial treatment of $\mathrm{mM}$ [73]. However, refractory or relapsed $\mathrm{mM}$ is still a problem. The mechanisms of $\mathrm{mM}$ resistance to melphalan may include the NFKB-dependent overexpression of DNA repair genes belonging to the Fanconi anaemia (FA) and BRCA pathways of HDR [74]. Curcumin, by inhibiting the NFkB [75] or FA/BRCA [76] pathways, reverses the multidrug-resistant phenotype of $\mathrm{mM}$. As such, curcumin has been proposed as a component of combinatorial therapies for multidrug-resistant $\mathrm{mM}$ [77]. In the case of DHC, its synthetic lethality toward BRCA1-deficient breast cancer lines [78] also indicates its potential in combinatorial cancer therapy. Therefore, our RAD52-overexpressing proteasome mutants may serve as models for research into HDR inhibitors that reverse the multidrug-resistant phenotypes of hard-to-treat malignancies.

\section{Materials and Methods}

\subsection{Yeast Strains}

The wild-type yeast strain BY4742 and its mutant derivatives rpn4- $\Delta$, rad23- $\Delta$, mag1- $\Delta$ and $r a d 52-\Delta$ were obtained from Euroscarf (Oberursel, Germany). The mutant strains with the deregulated essential proteasomal subunits YPL and YRL were created earlier [19,24], and YRPL was created in this work. The genotypes of all used strains are described in Table S1.

The oligonucleotides and plasmids used in the work are described in Tables S2 and S3.

\subsection{RT-PCR}

RT-PCR analysis was performed as described earlier [50]. Briefly, total RNA was isolated from yeast cell cultures grown to the logarithmic growth phase. cDNA was synthesized using RevertAid reverse transcriptase and oligo (dT) primers (Thermo Fisher Scientific, Waltham, MA, USA). RT-PCR was performed on a LightCycler 480-II instrument (Roche Diagnostics, Indianapolis, IN, USA) with Eva Green dye (Syntol, Moscow, Russia). Actin (ACT1) was used as a reference. The data were processed with LightCycler 480 Software, version 1.5, and Microsoft Excel (Redmond, WA, USA). The oligonucleotides are listed in Table S2.

\section{3. $\beta$-. Galactosidase Assay}

The lac $Z$ reporter constructs consisted of the promoter of the tested gene translationally fused to the lac $Z$ coding region. LacZ activity was measured as previously described [19]. Briefly, cells in the logarithmic growth phase were pelleted and lysed in Z-buffer $\left(60 \mathrm{mM} \mathrm{NaH}_{2} \mathrm{PO}_{4}, 40 \mathrm{mM} \mathrm{Na}_{2} \mathrm{HPO}_{4}\right.$, $10 \mathrm{mM} \mathrm{KCl}, 1 \mathrm{mM} \mathrm{MgSO}_{4}, 50 \mathrm{mM}$ 2-mercaptoethanol) by vortexing with glass beads (Sigma, St. Louis, $\mathrm{MO}, \mathrm{USA})$. The cell lysates were clarified by centrifugation, mixed with ortho-nitrophenyl- $\beta$-galactoside (to $2 \mathrm{mg} / \mathrm{mL}$ ) and incubated at $37^{\circ} \mathrm{C}$ until a yellowish color formed. The reaction was stopped by the addition of $1 \mathrm{M} \mathrm{Na}_{2} \mathrm{CO}_{3}$. The total protein concentration and O-nitrophenol concentrations were 
measured spectrophotometrically using a NanoDrop ND-1000 (Thermo Fisher Scientific, Waltham, MA, USA).

\subsection{DamID Assay}

The activity of Dam methylase fused to Rpn4p was measured in a model system that we developed previously [34]. The activity of the Rpn4-tethered Dam methylase was measured by estimating the sensitivity of a nearby GATC site to MboI hydrolysis. The activity of the Dam-Rpn4 chimaera was normalized to the signal of Dam-Rpn4(C-A) lacking Rpn4-binding activity. Thus, the normalized signal reflects the specific binding of Rpn4.

\subsection{Stress Resistance Test}

Overnight cultures were diluted to OD600 $=1.0$, and five-fold serial dilutions were then prepared. Subsequently, 2.5 or $5 \mu \mathrm{L}$ of each dilution was spotted onto agar plates containing stressing agents, and the plates were then incubated at $30^{\circ} \mathrm{C}$ for several days. The control plates were incubated without stressing agents.

\subsection{Western Blot Analysis}

Western blot analysis of yeast lysates was performed to assess the accumulation of polyubiquitinated proteins as described earlier [19]. Western blot analysis of the Rad52-3ha levels was performed in the same way. The pRad52-3ha plasmid-expressing Rad52, fused with the C-terminal $3 \times$ HA epitope from its native promoter, was assembled from PCR fragments by recombinational cloning [79]. PCR fragments used in the plasmid assembly were obtained using the primers listed in Table S2. The Rad52-3ha levels were determined using a primary mouse monoclonal anti-HA antibody (1:1000, Sigma, USA) and an anti-mouse secondary antibody (1:100,000, Abcam, Cambridge HQ, UK). Tubulin was used as a loading control and was detected using a primary rat monoclonal antibody (1:1000, Abcam, UK) and an anti-rat secondary antibody (1:100,000, Abcam, UK). The images obtained were analyzed using ImageJ (https://imagej.nih.gov/ij/). The protein intensities were normalized to the actin or tubulin intensity.

\subsection{Proteasome Activity Measurement}

$20 \mathrm{~S}$ proteasome activity was measured as described previously [24].

\subsection{Mutation of Rpn4 Binding Sites Using the CRISPR/Cas9 System}

Spacers were designed using CRISPOR (http://crispor.tefor.net). Oligonucleotides encoding spacers (Table S2) were annealed and cloned into a BsaI-cut pCRCT vector [80]. Yeasts were co-transformed with pCRCT derivatives (Table S3) and PCR donor constructs. Each PCR donor carried an endonuclease (Xhol, XbaI or PstI) site instead of the GC-rich part of the PACE or PACE-like element. Yeast colonies were grown on synthetic selective media lacking uracil. Randomly picked colonies were screened for the presence of editing events using PCR followed by restriction analysis. The edited colonies were streaked to obtain single colonies, and the PACE mutations were verified by PCR followed by Sanger sequencing.

\subsection{Gene Repression with the CRISPR/Cas9 System}

Spacers targeting the SpyCas9 endonuclease to the PACE and PACE-like elements were designed using CRISPOR and cloned into pCRCT plasmids. The spacers were $14 \mathrm{nt}$ long. At this length, a spacer allows SpyCas9 to bind but not to cut a DNA target [81]. Thus, SpyCas9 specifically bound to the PACE or PACE-like element should inhibit the Rpn4 interaction with the corresponding element.

Supplementary Materials: Supplementary materials can be found at http://www.mdpi.com/1422-0067/21/21/ 8097/s1. 
Author Contributions: Conceptualization, D.S.K. and D.S.S.; methodology, D.S.K. and D.S.S.; software, D.S.K. and Y.P.L.; validation, D.S.K., D.S.S., N.I.N., and V.V.T.; formal analysis, D.S.K. and Y.P.L.; investigation, D.S.K., D.S.S., N.I.N., and V.V.T.; data curation, D.S.K. and Y.P.L.; writing-original draft preparation, D.S.K. and D.S.S.; writing-review and editing, D.S.K. and V.L.K.; visualization, D.S.K. and D.S.S.; supervision, V.L.K.; project administration, V.L.K.; funding acquisition, D.S.K. All authors have read and agreed to the published version of the manuscript.

Funding: This research was funded by the ministry of Science and Higher Education of the Russian Federation, grant number 075-15-2019-1660 (Figures 1-4 and Supplementary Data) and the Russian Foundation for Basic Research, grant number 18-29-07021 (Figures 5-7).

Acknowledgments: The pCRCT plasmid was a gift from Huimin Zhao (Addgene \#60621). We thank the Center for Precision Genome Editing and Genetic Technologies for Biomedicine, EIMB RAS for providing the computing power and techniques for the data analysis. This work was performed using the equipment of EIMB RAS "Genome" center (http://www.eimb.ru/ru1/ckp/ccu_genome_ce.php).

Conflicts of Interest: The authors declare no conflict of interest.

$\begin{array}{ll}\text { Abbreviations } \\ \text { 4-NQO } & \text { 4-Nitroquinoline-1-oxide } \\ \text { AZE } & \text { Azetidine-2-carboxylic acid } \\ \text { MMS } & \text { Methyl methanesulfonate } \\ \text { PACE } & \text { Proteasome-associated control element } \\ \text { MACE } & \text { MAG1-associated control element } \\ \text { RACE } & \text { RPN8-associated control element } \\ \text { SSBs } & \text { DNA single-strand breaks } \\ \text { DSBs } & \text { DNA double-strand breaks } \\ \text { DDR } & \text { DNA damage response } \\ \text { BER } & \text { Base excision repair } \\ \text { NER } & \text { Nucleotide excision repair } \\ \text { MMR } & \text { Mismatch repair } \\ \text { HDR } & \text { Homology-directed repair } \\ \text { NHEJ } & \text { Non-homologous end joining } \\ \text { MMEJ } & \text { Microhomology-mediated end joining } \\ \text { SUMO } & \text { Small ubiquitin-like modifier } \\ \text { CRISPR } & \text { Clustered regularly interspaced short palindromic repeats } \\ \text { PAM } & \text { Protospacer-adjacent motif } \\ \text { Cas9 } & \text { CRISPR-associated protein 9 } \\ \text { sgRNA } & \text { Single guide RNA } \\ \text { RT-PCR } & \text { Real-time polymerase chain reaction } \\ \text { UV } & \text { Ultraviolet } \\ \text { DHC } & \text { Dihydrocoumarin } \\ \text { TopIcc } & \text { Topoisomerase I-DNA covalent complex } \\ \text { MM } & \text { Multiple myeloma } \\ \text { VMP } & \text { Bortezomib, melphalan, and prednisone regimen } \\ \text { HDAC } & \text { Histone deacetylase } \\ \text { FA } & \text { Fanconi anaemia } \\ & \end{array}$

\section{References}

1. Chatterjee, N.; Walker, G.C. Mechanisms of DNA damage, repair, and mutagenesis. Environ. Mol. Mutagen. 2017, 58, 235-263. [CrossRef] [PubMed]

2. Tubbs, A.; Nussenzweig, A. Endogenous DNA damage as a source of genomic instability in cancer. Cell 2017, 168, 644-656. [CrossRef]

3. Cannan, W.J.; Pederson, D.S. Mechanisms and consequences of double-strand DNA break formation in chromatin. J. Cell. Physiol. 2016, 231, 3-14. [CrossRef]

4. Hoeijmakers, J.H. DNA damage, aging, and cancer. N. Engl. J. Med. 2009, 361, 1475-1485. [CrossRef] 
5. Giglia-Mari, G.; Zotter, A.; Vermeulen, W. DNA damage response. Cold Spring Harb. Perspect. Biol. 2011, 3, a000745. [CrossRef]

6. Frosina, G. Overexpression of enzymes that repair endogenous damage to DNA. Eur. J. Biochem. 2000, 267, 2135-2149. [CrossRef]

7. Ortolan, T.G.; Chen, L.; Tongaonkar, P.; Madura, K. Rad23 stabilizes Rad4 from degradation by the Ub/proteasome pathway. Nucleic Acids Res. 2004, 32, 6490-6500. [CrossRef]

8. Skoneczna, A.; McIntyre, J.; Skoneczny, M.; Policinska, Z.; Sledziewska-Gojska, E. Polymerase eta is a short-lived, proteasomally degraded protein that is temporarily stabilized following UV irradiation in Saccharomyces cerevisiae. J. Mol. Biol. 2007, 366, 1074-1086. [CrossRef] [PubMed]

9. Chen, X.; Ruggiero, C.; Li, S. Yeast Rpb9 plays an important role in ubiquitylation and degradation of Rpb1 in response to UV-induced DNA damage. Mol. Cell. Biol. 2007, 27, 4617-4625. [CrossRef]

10. Ribar, B.; Prakash, L.; Prakash, S. Requirement of ELC1 for RNA polymerase II polyubiquitylation and degradation in response to DNA damage in Saccharomyces cerevisiae. Mol. Cell. Biol. 2006, 26, 3999-4005. [CrossRef]

11. Hauer, M.H.; Seeber, A.; Singh, V.; Thierry, R.; Sack, R.; Amitai, A.; Kryzhanovska, M.; Eglinger, J.; Holcman, D.; Owen-Hughes, T.; et al. Histone degradation in response to DNA damage enhances chromatin dynamics and recombination rates. Nat. Struct. Mol. Biol. 2017, 24, 99-107. [CrossRef]

12. Garcia-Rodriguez, N.; Wong, R.P.; Ulrich, H.D. Functions of ubiquitin and SUMO in DNA replication and replication stress. Front. Genet. 2016, 7, 87. [CrossRef]

13. Xie, Y.; Varshavsky, A. RPN4 is a ligand, substrate, and transcriptional regulator of the 26S proteasome: A negative feedback circuit. Proc. Natl. Acad. Sci. USA 2001, 98, 3056-3061. [CrossRef]

14. Mannhaupt, G.; Schnall, R.; Karpov, V.; Vetter, I.; Feldmann, H. Rpn4p acts as a transcription factor by binding to PACE, a nonamer box found upstream of $26 \mathrm{~S}$ proteasomal and other genes in yeast. FEBS Lett. 1999, 450, 27-34. [CrossRef]

15. London, M.K.; Keck, B.I.; Ramos, P.C.; Dohmen, R.J. Regulatory mechanisms controlling biogenesis of ubiquitin and the proteasome. FEBS Lett. 2004, 567, 259-264. [CrossRef]

16. Hahn, J.S.; Neef, D.W.; Thiele, D.J. A stress regulatory network for co-ordinated activation of proteasome expression mediated by yeast heat shock transcription factor. Mol. Microbiol. 2006, 60, 240-251. [CrossRef]

17. Owsianik, G.; Balzi, L.; Ghislain, M. Control of 26S proteasome expression by transcription factors regulating multidrug resistance in Saccharomyces cerevisiae. Mol. Microbiol. 2002, 43, 1295-1308. [CrossRef]

18. Karpov, D.S.; Osipov, S.A.; Preobrazhenskaya, O.V.; Karpov, V.L. Rpn4p is a positive and negative transcriptional regulator of the ubiquitin-proteasome system. Mol. Biol. 2008, 42, 456-462. [CrossRef]

19. Karpov, D.S.; Spasskaya, D.S.; Tutyaeva, V.V.; Mironov, A.S.; Karpov, V.L. Proteasome inhibition enhances resistance to DNA damage via upregulation of Rpn4-dependent DNA repair genes. FEBS Lett. 2013, 587, 3108-3114. [CrossRef]

20. Jelinsky, S.A.; Estep, P.; Church, G.M.; Samson, L.D. Regulatory networks revealed by transcriptional profiling of damaged Saccharomyces cerevisiae cells: Rpn4 links base excision repair with proteasomes. Mol. Cell. Biol. 2000, 20, 8157-8167. [CrossRef]

21. Le Tallec, B.; Barrault, M.B.; Courbeyrette, R.; Guerois, R.; Marsolier-Kergoat, M.C.; Peyroche, A. 20S proteasome assembly is orchestrated by two distinct pairs of chaperones in yeast and in mammals. Mol. Cell 2007, 27, 660-674. [CrossRef]

22. Le Tallec, B.; Barrault, M.B.; Guerois, R.; Carre, T.; Peyroche, A. Hsm3/S5b participates in the assembly pathway of the $19 \mathrm{~S}$ regulatory particle of the proteasome. Mol. Cell 2009, 33, 389-399. [CrossRef]

23. Tallec, B.L.; Peyroche, A. Using DNA damage sensitivity phenotypes to characterize mutations affecting proteasome function. Methods Mol. Biol. 2012, 832, 363-371. [CrossRef] [PubMed]

24. Karpov, D.S.; Spasskaya, D.S.; Nadolinskaia, N.I.; Tutyaeva, V.V.; Lysov, Y.P.; Karpov, V.L. Deregulation of the $19 \mathrm{~S}$ proteasome complex increases yeast resistance to 4-NQO and oxidative stress via upregulation of Rpn4- and proteasome-dependent stress responsive genes. FEMS Yeast Res. 2019, 19, foz002. [CrossRef]

25. Karpov, D.S.; Tutyaeva, V.V.; Karpov, V.L. Mapping of yeast Rpn4p transactivation domains. FEBS Lett. 2008, 582, 3459-3464. [CrossRef]

26. Wang, X.; Xu, H.; Ha, S.W.; Ju, D.; Xie, Y. Proteasomal degradation of Rpn4 in Saccharomyces cerevisiae is critical for cell viability under stressed conditions. Genetics 2010, 184, 335-342. [CrossRef] 
27. Gasch, A.P.; Moses, A.M.; Chiang, D.Y.; Fraser, H.B.; Berardini, M.; Eisen, M.B. Conservation and evolution of cis-regulatory systems in ascomycete fungi. PLoS Biol. 2004, 2, e398. [CrossRef]

28. Shirozu, R.; Yashiroda, H.; Murata, S. Identification of minimum Rpn4-responsive elements in genes related to proteasome functions. FEBS Lett. 2015, 589, 933-940. [CrossRef]

29. Gasch, A.P.; Huang, M.; Metzner, S.; Botstein, D.; Elledge, S.J.; Brown, P.O. Genomic expression responses to DNA-damaging agents and the regulatory role of the yeast ATR homolog Mec1p. Mol. Biol. Cell 2001, 12, 2987-3003. [CrossRef]

30. Fry, R.C.; Sambandan, T.G.; Rha, C. DNA damage and stress transcripts in Saccharomyces cerevisiae mutant sgs1. Mech. Ageing Dev. 2003, 124, 839-846. [CrossRef]

31. Benton, M.G.; Somasundaram, S.; Glasner, J.D.; Palecek, S.P. Analyzing the dose-dependence of the Saccharomyces cerevisiae global transcriptional response to methyl methanesulfonate and ionizing radiation. BMC Genom. 2006, 7, 305. [CrossRef]

32. Jaehnig, E.J.; Kuo, D.; Hombauer, H.; Ideker, T.G.; Kolodner, R.D. Checkpoint kinases regulate a global network of transcription factors in response to DNA damage. Cell Rep. 2013, 4, 174-188. [CrossRef] [PubMed]

33. Kapranov, A.B.; Kuryatova, M.V.; Preobrazhenskaya, O.V.; Tutyaeva, V.V.; Stucka, R.; Feldmann, H.; Karpov, V.L. Isolation and identification of PACE-binding protein Rpn4, a new transcriptional activator regulating 26S-proteasomal and other genes. Mol. Biol. 2001, 35, 356-364. [CrossRef]

34. Spasskaya, D.S.; Karpov, D.S.; Karpov, V.L. Escherichia coli Dam-methylase as a molecular tool for mapping binding sites of the yeast transcription factor Rpn4. Mol. Biol. 2011, 45, 591-599. [CrossRef]

35. Ju, D.; Wang, X.; Ha, S.W.; Fu, J.; Xie, Y. Inhibition of proteasomal degradation of rpn4 impairs nonhomologous end-joining repair of DNA double-strand breaks. PLoS ONE 2010, 5, e9877. [CrossRef]

36. Jansen, L.E.; Verhage, R.A.; Brouwer, J. Preferential binding of yeast Rad4.Rad23 complex to damaged DNA. J. Biol. Chem. 1998, 273, 33111-33114. [CrossRef]

37. Guzder, S.N.; Habraken, Y.; Sung, P.; Prakash, L.; Prakash, S. Reconstitution of yeast nucleotide excision repair with purified Rad proteins, replication protein A, and transcription factor TFIIH. J. Biol. Chem. 1995, 270, 12973-12976. [CrossRef]

38. Zhu, Y.; Xiao, W. Pdr3 is required for DNA damage induction of MAG1 and DDI1 via a bi-directional promoter element. Nucleic Acids Res. 2004, 32, 5066-5075. [CrossRef]

39. Spasskaya, D.S.; Karpov, D.S.; Mironov, A.S.; Karpov, V.L. Transcription factor Rpn4 promotes a complex antistress response in Saccharomyces cerevisiae cells exposed to methyl methanesulfonate. Mol. Biol. 2014, 48, 141-149. [CrossRef]

40. Krogh, B.O.; Symington, L.S. Recombination proteins in yeast. Annu. Rev. Genet. 2004, 38, 233-271. [CrossRef] [PubMed]

41. Mannhaupt, G.; Feldmann, H. Genomic evolution of the proteasome system among hemiascomycetous yeasts. J. Mol. Evol. 2007, 65, 529-540. [CrossRef] [PubMed]

42. Karpov, D.S.; Lysov, Y.P.; Karpov, V.L. Evolution of the system of coordinate regulation of proteasomal gene expression in the yeast class Saccharomycetes. Mol. Biol. 2019, 53, 1029-1037. [CrossRef]

43. Krol, K.; Brozda, I.; Skoneczny, M.; Bretner, M.; Skoneczna, A. A genomic screen revealing the importance of vesicular trafficking pathways in genome maintenance and protection against genotoxic stress in diploid Saccharomyces cerevisiae cells. PLoS ONE 2015, 10, e0120702. [CrossRef]

44. Flores-Rozas, H.; Jaafar, L.; Xia, L. The role of DNA mismatch repair and recombination in the processing of DNA alkylating damage in living yeast cells. Adv. Biosci. Biotechnol. 2015, 6, 408-418. [CrossRef]

45. Hayashi, M.; Umezu, K. Homologous recombination is required for recovery from oxidative DNA damage. Genes Genet. Syst. 2017, 92, 73-80. [CrossRef] [PubMed]

46. Arima, Y.; Nishigori, C.; Takeuchi, T.; Oka, S.; Morimoto, K.; Utani, A.; Miyachi, Y. 4-Nitroquinoline 1-oxide forms 8-hydroxydeoxyguanosine in human fibroblasts through reactive oxygen species. Toxicol. Sci. 2006, 91, 382-392. [CrossRef]

47. Yip, M.C.J.; Bodnar, N.O.; Rapoport, T.A. Ddi1 is a ubiquitin-dependent protease. Proc. Natl. Acad. Sci. USA 2020, 117, 7776-7781. [CrossRef] [PubMed]

48. Serbyn, N.; Noireterre, A.; Bagdiul, I.; Plank, M.; Michel, A.H.; Loewith, R.; Kornmann, B.; Stutz, F. The aspartic protease Ddi1 contributes to DNA-protein crosslink repair in yeast. Mol. Cell 2020, 77, 1066-1079. [CrossRef]

49. Svoboda, M.; Konvalinka, J.; Trempe, J.F.; Grantz Saskova, K. The yeast proteases Ddi1 and Wss1 are both involved in the DNA replication stress response. DNA Repair (Amst) 2019, 80, 45-51. [CrossRef] 
50. Bubis, J.A.; Spasskaya, D.S.; Gorshkov, V.A.; Kjeldsen, F.; Kofanova, A.M.; Lekanov, D.S.; Gorshkov, M.V.; Karpov, V.L.; Tarasova, I.A.; Karpov, D.S. Rpn4 and proteasome-mediated yeast resistance to ethanol includes regulation of autophagy. Appl. Microbiol. Biotechnol. 2020, 104, 4027-4041. [CrossRef]

51. Russell, S.J.; Reed, S.H.; Huang, W.; Friedberg, E.C.; Johnston, S.A. The 19S regulatory complex of the proteasome functions independently of proteolysis in nucleotide excision repair. Mol. Cell 1999, 3, 687-695. [CrossRef]

52. Gillette, T.G.; Huang, W.; Russell, S.J.; Reed, S.H.; Johnston, S.A.; Friedberg, E.C. The 19S complex of the proteasome regulates nucleotide excision repair in yeast. Genes Dev. 2001, 15, 1528-1539. [CrossRef]

53. Olaharski, A.J.; Rine, J.; Marshall, B.L.; Babiarz, J.; Zhang, L.; Verdin, E.; Smith, M.T. The flavoring agent dihydrocoumarin reverses epigenetic silencing and inhibits sirtuin deacetylases. PLoS Genet. 2005, 1, e77. [CrossRef]

54. Chen, C.C.; Huang, J.S.; Wang, T.H.; Kuo, C.H.; Wang, C.J.; Wang, S.H.; Leu, Y.L. Dihydrocoumarin, an HDAC inhibitor, increases DNA damage sensitivity by inhibiting Rad52. Int. J. Mol. Sci. 2017, 18, 2655. [CrossRef]

55. Maynard, S.; Fang, E.F.; Scheibye-Knudsen, M.; Croteau, D.L.; Bohr, V.A. DNA damage, DNA repair, aging, and neurodegeneration. Cold Spring Harb. Perspect. Biol. 2015, 5, a025130. [CrossRef]

56. Yeh, C.D.; Richardson, C.D.; Corn, J.E. Advances in genome editing through control of DNA repair pathways. Nat. Cell Biol. 2019, 21, 1468-1478. [CrossRef]

57. Dantuma, N.P.; Heinen, C.; Hoogstraten, D. The ubiquitin receptor Rad23: At the crossroads of nucleotide excision repair and proteasomal degradation. DNA Repair (Amst) 2009, 8, 449-460. [CrossRef] [PubMed]

58. Kaplun, L.; Tzirkin, R.; Bakhrat, A.; Shabek, N.; Ivantsiv, Y.; Raveh, D. The DNA damage-inducible UbL-UbA protein Ddi1 participates in Mec1-mediated degradation of Ho endonuclease. Mol. Cell. Biol. 2005, 25, 5355-5362. [CrossRef] [PubMed]

59. Bertolaet, B.L.; Clarke, D.J.; Wolff, M.; Watson, M.H.; Henze, M.; Divita, G.; Reed, S.I. UBA domains mediate protein-protein interactions between two DNA damage-inducible proteins. J. Mol. Biol. 2001, 313, 955-963. [CrossRef]

60. de Graaf, B.; Clore, A.; McCullough, A.K. Cellular pathways for DNA repair and damage tolerance of formaldehyde-induced DNA-protein crosslinks. DNA Repair (Amst) 2009, 8, 1207-1214. [CrossRef] [PubMed]

61. Nakano, T.; Katafuchi, A.; Matsubara, M.; Terato, H.; Tsuboi, T.; Masuda, T.; Tatsumoto, T.; Pack, S.P.; Makino, K.; Croteau, D.L.; et al. Homologous recombination but not nucleotide excision repair plays a pivotal role in tolerance of DNA-protein cross-links in mammalian cells. J. Biol. Chem. 2009, 284, 27065-27076. [CrossRef] [PubMed]

62. Ohsawa, K.-I.; Furihata, C.; Mori, M.; Ikui, E. Ability of N-methyl-N'-nitro-N-nitrosoguanidine, 4-nitroquinoline 1-oxide, dimethylnitrosome, and $\mathrm{NaCl}$ to induce inscheduled DNA synthesis, stimulate replicative DNA synthesis, and produce DNA single-strand breaks in pyloric mucosa of rat stomach. Mutat. Res. 1993, 287, 307-319. [CrossRef]

63. Miao, Z.H.; Rao, V.A.; Agama, K.; Antony, S.; Kohn, K.W.; Pommier, Y. 4-nitroquinoline-1-oxide induces the formation of cellular topoisomerase I-DNA cleavage complexes. Cancer Res. 2006, 66, 6540-6545. [CrossRef] [PubMed]

64. Pommier, Y.; Redon, C.; Rao, V.A.; Seiler, J.A.; Sordet, O.; Takemura, H.; Antony, S.; Meng, L.; Liao, Z.; Kohlhagen, G.; et al. Repair of and checkpoint response to topoisomerase I-mediated DNA damage. Mutat. Res. 2003, 532, 173-203. [CrossRef] [PubMed]

65. Barretina, J.; Caponigro, G.; Stransky, N.; Venkatesan, K.; Margolin, A.A.; Kim, S.; Wilson, C.J.; Lehar, J.; Kryukov, G.V.; Sonkin, D.; et al. The cancer cell line encyclopedia enables predictive modelling of anticancer drug sensitivity. Nature 2012, 483, 603-607. [CrossRef]

66. Sacher, M.; Pfander, B.; Hoege, C.; Jentsch, S. Control of Rad52 recombination activity by double-strand break-induced SUMO modification. Nat. Cell Biol. 2006, 8, 1284-1290. [CrossRef]

67. Cole, G.M.; Schild, D.; Mortimer, R.K. Two DNA repair and recombination genes in Saccharomyces cerevisiae, RAD52 and RAD54, are induced during meiosis. Mol. Cell. Biol. 1989, 9, 3101-3104. [CrossRef]

68. Cole, G.M.; Schild, D.; Lovett, S.T.; Mortimer, R.K. Regulation of RAD54- and RAD52-lacZ gene fusions in Saccharomyces cerevisiae in response to DNA damage. Mol. Cell. Biol. 1987, 7, 1078-1084. [CrossRef]

69. Asleson, E.N.; Livingston, D.M. Investigation of the stability of yeast rad52 mutant proteins uncovers post-translational and transcriptional regulation of Rad52p. Genetics 2003, 163, 91-101. 
70. Dornfeld, K.J.; Livingston, D.M. Effects of controlled RAD52 expression on repair and recombination in Saccharomyces cerevisiae. Mol. Cell. Biol. 1991, 11, 2013-2017. [CrossRef]

71. Matuo, R.; Sousa, F.G.; Soares, D.G.; Bonatto, D.; Saffi, J.; Escargueil, A.E.; Larsen, A.K.; Henriques, J.A. Saccharomyces cerevisiae as a model system to study the response to anticancer agents. Cancer Chemother. Pharmacol. 2012, 70, 491-502. [CrossRef] [PubMed]

72. Wang, S.H.; Lin, P.Y.; Chiu, Y.C.; Huang, J.S.; Kuo, Y.T.; Wu, J.C.; Chen, C.C. Curcumin-mediated HDAC inhibition suppresses the DNA damage response and contributes to increased DNA damage sensitivity. PLoS ONE 2015, 10, e0134110. [CrossRef] [PubMed]

73. San Miguel, J.F.; Schlag, R.; Khuageva, N.K.; Dimopoulos, M.A.; Shpilberg, O.; Kropff, M.; Spicka, I.; Petrucci, M.T.; Palumbo, A.; Samoilova, O.S.; et al. Bortezomib plus melphalan and prednisone for initial treatment of multiple myeloma. N. Engl. J. Med. 2008, 359, 906-917. [CrossRef]

74. Chen, Q.; Van der Sluis, P.C.; Boulware, D.; Hazlehurst, L.A.; Dalton, W.S. The FA/BRCA pathway is involved in melphalan-induced DNA interstrand cross-link repair and accounts for melphalan resistance in multiple myeloma cells. Blood 2005, 106, 698-705. [CrossRef]

75. Bharti, A.C.; Donato, N.; Singh, S.; Aggarwal, B.B. Curcumin (diferuloylmethane) down-regulates the constitutive activation of nuclear factor-kappa B and IkappaBalpha kinase in human multiple myeloma cells, leading to suppression of proliferation and induction of apoptosis. Blood 2003, 101, 1053-1062. [CrossRef] [PubMed]

76. Xiao, H.; Xiao, Q.; Zhang, K.; Zuo, X.; Shrestha, U.K. Reversal of multidrug resistance by curcumin through FA/BRCA pathway in multiple myeloma cell line MOLP-2/R. Ann. Hematol. 2010, 89, 399-404. [CrossRef]

77. Sung, B.; Kunnumakkara, A.B.; Sethi, G.; Anand, P.; Guha, S.; Aggarwal, B.B. Curcumin circumvents chemoresistance in vitro and potentiates the effect of thalidomide and bortezomib against human multiple myeloma in nude mice model. Mol. Cancer Ther. 2009, 8, 959-970. [CrossRef]

78. Zhang, B.; Lyu, J.; Yang, E.J.; Liu, Y.; Wu, C.; Pardeshi, L.; Tan, K.; Chen, Q.; Xu, X.; Deng, C.X.; et al. Class I histone deacetylase inhibition is synthetic lethal with BRCA1 deficiency in breast cancer cells. Acta Pharm. Sin. B 2020, 10, 615-627. [CrossRef]

79. van Leeuwen, J.; Andrews, B.; Boone, C.; Tan, G. Rapid and efficient plasmid construction by homologous recombination in yeast. Cold Spring Harb. Protoc. 2015, 2015, 853-861. [CrossRef]

80. Bao, Z.; Xiao, H.; Liang, J.; Zhang, L.; Xiong, X.; Sun, N.; Si, T.; Zhao, H. Homology-integrated CRISPR-Cas (HI-CRISPR) system for one-step multigene disruption in Saccharomyces cerevisiae. ACS Synth. Biol. 2015, 4, 585-594. [CrossRef]

81. Dahlman, J.E.; Abudayyeh, O.O.; Joung, J.; Gootenberg, J.S.; Zhang, F.; Konermann, S. Orthogonal gene knockout and activation with a catalytically active Cas9 nuclease. Nat. Biotechnol. 2015, 33, 1159-1161. [CrossRef] [PubMed]

Publisher's Note: MDPI stays neutral with regard to jurisdictional claims in published maps and institutional affiliations.

(C) 2020 by the authors. Licensee MDPI, Basel, Switzerland. This article is an open access article distributed under the terms and conditions of the Creative Commons Attribution (CC BY) license (http://creativecommons.org/licenses/by/4.0/). 